\title{
Source Tracing and Application of Regional Natural Materials in Ecological Buildings
}

\author{
Meng Yuan \\ Doctoral Candidate, School of Art \& Design, Wuhan University of Technology \\ Lecturer, College of Textile Engineering and Art, Anhui Agricultural University \\ Hefei, Anhui, China \\ E-mail: 307597730@qq.com
}

\begin{abstract}
In this paper the ecological limitations of natural materials in the origin of creation are proposed. By tracing the source of regional natural materials in ecological buildings and by taking contemporary works as examples, it is analyzed that the sustainable development of modern ecological buildings is an inevitable trend in the holistic view of establishment of the organic relationship between human beings and environment.
\end{abstract}

Keywords: regionality; natural materials; ecological building; sustainable development

\section{ECOLOGICAL LIMITATIONS OF REGIONAL NATURAL MATERIALS IN THE ORIGIN OF CREATION}

Marx understood the primitive art in the preamble to "Critique of Political Economy" today as: "They can still give us artistic enjoyment, and in some respects they are a

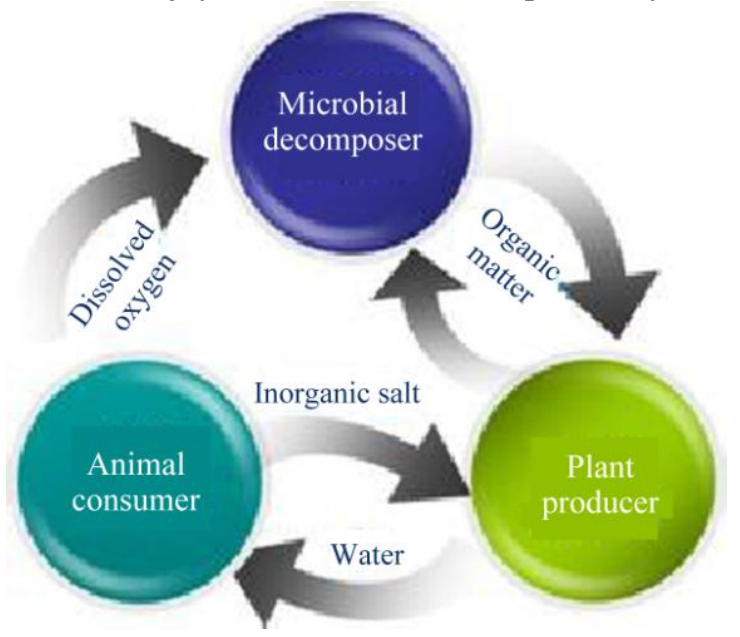

Fig. 1 Food pyramid chain

Starting from the origin of human beings, it can be found that the ecological limitations of regional natural materials have always determined the level of creation. Traditional culture contains a lot of intellectual heritage arising out of the traditional ecological view. For example, the natural ontological awareness of "Harmony between man and nature", the ecological ethic concept of "Love relatives, and then love people and things", the ecological aesthetic concept of "Realize that human life activities are based on life in the universe", "A man without distant care must have near sorrow", the ecological value orientation normative and unattainable model. Primitive art provides a model for our artistic design process today and it is also a source. This indigenous dialogue with nature is a "design that is originated in human hearts and is similar to the evolution of living creatures" [1].

\section{A. Ecological Design Thinking under the Limitations of Regional Natural Materials}

The biosphere in nature is a circular food pyramid chain (Fig. 1), where human beings are the only social groups who have self-consciousness and change the natural world, they evolved from the natural world, they belong to the natural world, but they transcend the natural world, they are closely related to nature, but the relationship between them is very subtle. The relationship between human beings and living environment constitutes an ecosystem (Fig. 2).

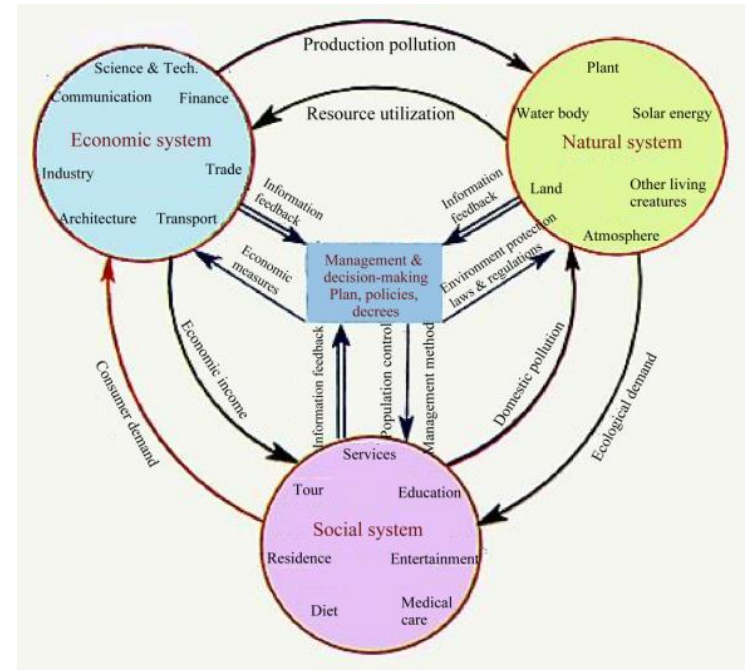

Fig. 2 Ecosystem

of "The efforts today benefit the current and future generations", etc., all these highlight the use of regional materials in the process of growing together with nature, and has a sustainable development that cannot be ignored.

Tracing back to the early days of ecological building, the first on the list of Chinese cultural ancestors on the China Millennium Monument is Youchao, who opened up the precedent of earliest buildings. The most important cultural feature is that the ecological design thinking of functional beauty and form beauty of the original buildings is formed under the limitations of regional natural 
materials. This not only studies the relationship between man and nature, people's lifestyle and social life, but also involves the human society and various cultural patterns.

\section{B. Material is the First Element of the Design Elements}

Among the constituent elements of design beauty, materials are the first element. Thinking of the activities of creation of our first ancestor Youchao, if there are no branches and grass stems, "Even a clever housewife cannot cook a meal without rice", and not mention the early buildings. If the production and life at that time has reached a certain stage, the available materials must be more suitable for human use, and it would not be necessary to develop over such a long time. Obviously, materials are the source of design. The shortage of materials determines the limitations of productivity and constrains the possibility of design beauty, whereas the earliest building materials, that is, indigenous regional natural materials, are the primary element for creating ecological beauty.

Materials are not only the embodiment of the Youchao culture in the primitive period. Even today, they still determine the functionality of the products, the feasibility of the structure and the beauty of the form. In the "Artificers' Record" written in the period before the Qin Dynasty it was said: "Examine the bend and straightness, then determine use of the kinds of five materials, check the products and use the qualified ones."'[2] It is indicated that since the ancient times, craftsmen have long understand that they must carefully look at the material's bend and straightness for fabrication of utensils in order to handle them according to different circumstances. This fully shows that the material beauty is the first element among materials, structures and functions.

As far as the surface effect of the material is concerned, the color, luster and texture of the material constitute the texture of the material. [3] When people come into contact with the same material many times, they will have a mindset, and they will have a sense of association and synaesthesia for the material texture, and even move from the visual, olfactory or tactile sense to the psychological level. Natural materials are more able to show unique regional characteristics under the restriction of ecological beauty.

\section{TRACING TO CULTURAL ORIGIN OF REGIONAL NATURAL MATERIALS IN NEST BUILDINGS}

Architectural culture is a kind of permanent material image culture. With the development advancing with the times, the nest-building form created by the first ancestor Youchao can be called the earliest green buildings. In ancient times, buildings were particularly limited by regional materials. Therefore, tracing the use of materials at that time is particularly necessary for studying how to achieve the sustainable development required by today's buildings.

\section{A. Application of Regional Natural Materials in the "Nest Dwellings" Rriginated by the First Ancestor Youchao}

The first ancestor who was regarded as the "founder" by the building industry - Youchao, was the originator of "nest dwellings". According to the record in "Zhuangzi • The robber Zhi": "They pick up the acorns in the day and stay on trees at night, so they are called Youchao's people". A hundred years later, Han Feizi also described vividly and concretely in his famous book "The Five Vermin": "In the ancient period, there were few people but many animals, so the people could not conquer the birds, animals, vermin and snakes. There was a saint who used trees to build nests so as to avoid hazards, and the people were happy with this, and made him be their king, and called him "Youchao." It can be seen that the situation in which people lived together with the beasts, worms and snakes was extremely difficult. The first ancestor who lived in the Chaohu Lake Basin - Youchao, learned from the birds and built the nests on the acorn trees mostly in Chaohu Lake Basin, and the acorn trees became the most important regional natural material for early nest dwelling. The creation of "Primitive House" corresponds to the sustainable development of the environment and also satisfies the two major principles of use of local materials, namely, the avoidance principle of risks and the proximity principle of foods.

The nest dwellings built on the acorn trees realized the application of the earliest regional natural materials in the nest buildings and thus avoided the attack of the birds, beasts, worms and snakes using the unique shape of the trees. The fruit on the acorn trees (Fig. 3), etc. also become one of the main foods that the ancestors discovered and satisfied their hunger earlier. The ancestors who had previously been unable to satisfy their hunger by taking the edible acorns outside their nests, under the leadership of the first ancestor Youchao, gradually achieved the diet culture of first eating the leaves and wild fruits, and later groping from the branches to stem roots, barks and rhizomes. It can be said that the nest dwelling is the earliest ecological building. These two major principles are inseparable from the regional natural material - the acorn tree, which completed the most basic practical functions under the conditions of sustainable development of ecological buildings.

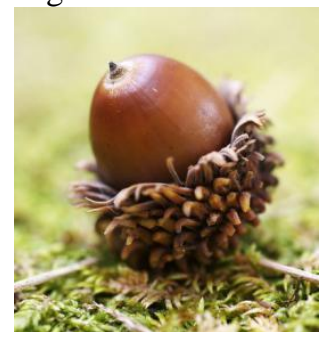

Fig. 3 Acorn

Just as said in the book "Charismatic Genes of Villa Culture": "Since the time of Youchao who built nests on trees, and taught people 'to pick up the acorns in the day time and perch on trees at night', he opened up the earliest and most primitive architectural forms of human beings, with the continuous progress of human civilization, the original so-called 'building', began to be superimposed and extended in the aspects of form, function, connotation, 
style and culture. The Hong Kong science writer Zhao Guangchao also once said in "More than China's Wooden Architecture": "For thousands of years, the great Youchao have been speaking - for thousands of years, wooden buildings have become a synonym of Chinese building and have widely influencing the adjacent countries, and have formed an independent and self-contained architectural tradition outside the stone-based Western architecture." It can be seen that the first ancestor Youchao guided the original "inheritance and innovation" of architectural culture. The living conditions of human beings developed from the original nests on separate trees to the nests on multiple trees, to the dwellings on the ground and the buildings on stilts. (Fig. 4) and until today's high-rise buildings, wooden buildings have become the source of Chinese architectural history.

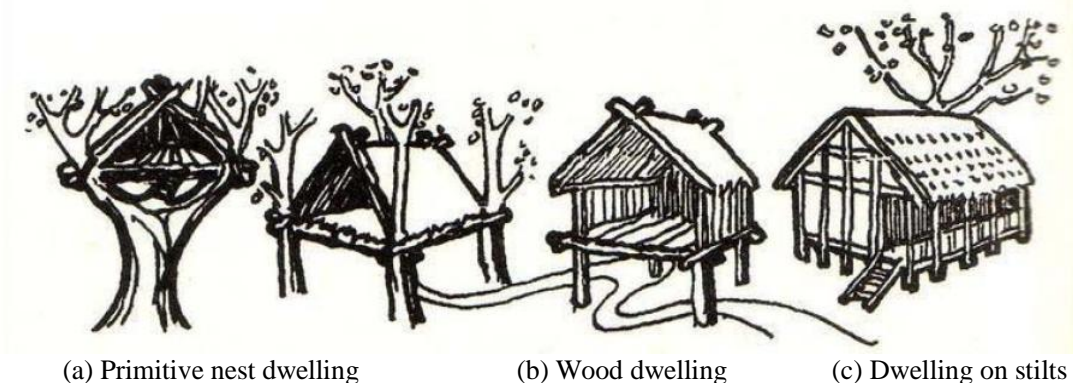

Fig. 4 Evolution of primitive living on trees

B. Application of Regional Natural Materials in the above Ground Dwellings of the Imperial Ancestor Youchao

Youchao's descendents lived and grew in the south. Their leader was the common leader of the Central Plains, who was called the imperial ancestor Youchao, called "Nest emperor" for short, and also known as "ancient Huangshi". Such an authoritative title of honor is not only due to the fact that the first ancestor Youchao and his clan used the natural conditions of the local acorn trees as the materials to make nests and benefit the world, what is more important is that it is related to the further application and improvement of the regional natural materials by the imperial ancestor Youchao in the history of architecture.

The difference between the first ancestor and imperial ancestor lies in the difference in time and merits. In 1926, Li Yueduan commented and Yin Shuixin revised a textbook "Reading History of the State" for "Secondary Schools of New Educational System". They very clearly distinguished the merits of the first ancestor Youchao and the imperial ancestor Youchao: "The early Youchao built the nests with trees and the late Youchao wove the reeds into door in order to change the wind direction in the cave dwelling in the wilderness and eliminate the hazards of birds and beasts and wind and rain." Indicating that the early Youchao, that is, the first ancestor Youchao's merit lies in teaching people to build the nests with trees; the late Youchao, that is, the imperial ancestor Youchao's merit lies in teaching people to further refine the regional natural materials, using the hibiscus to build houses, and using the reeds to make doors in order to resist the attacks of wild animals and wind and rain by the way of "weaving hibiscus to build houses and using reeds to make doors", and changing "nest dwelling" on the trees to "dwelling in houses" on the ground. This top-down return is an epoch-making innovation and invention again for human habitation.

(1) The "Hibiscus" in "weaving hibiscus to build houses" (Fig. 5) is a deciduous shrub of the Malvaceae family, also known as rose of sharon, which can be woven into the main part of the fence and shed. The so-called "weaving hibiscus to build houses" is to weave reeds into walls and build houses on the ground.

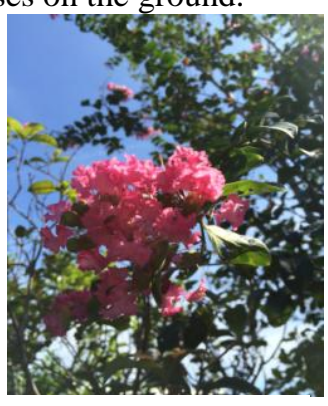

Fig. 5 Hibiscus

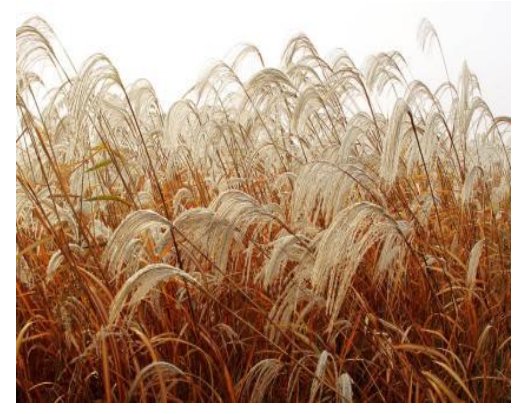

Fig. 6 Silvergrass

(2) The "Reed" in "using reeds to make doors" is also called "Silvergrass" (Fig. 6). It is like the reeds and its stems can be woven into reed mat. Like the hibiscus, it also became a building material for the imperial ancestor Youchao to use locally to make doors. But just the "door" at that time could not be called a "door" in the true sense. Because from the perspective of the inscription “棔” on bones or tortoise shells of the Shang Dynasty, it looks like there are two "door leaves" $\mathbf{p}, \mathbf{q}$ at the entrance $\boldsymbol{H}$ to the house. In some inscriptions of 9 , the upper frame + of the entrance to the house was omitted, written as 明, its shape is like tree sticks tied together. The original meaning 
of creating words refers to the two door leaves that can be opened and closed at the entrance of the house and is

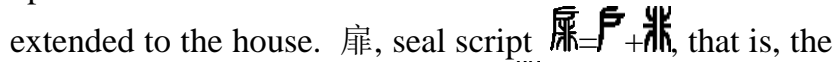
combination of "house, door" and "䭽, not", means similar

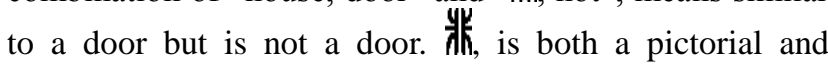
phonetic character, meaning a deny. The original meaning of creating this character does not refer to the main entrance, that is, the small fence gate that is set at the entrance to the court. "Using reeds to make doors" means using the materials such as the trees, hibiscus strips, thatch, reeds, etc. to make the door of the house on the ground.

"Using reeds to make doors" is another great invention of the imperial ancestor Youchao: By setting up "doors", the residents can easily go in and out, and once "the door" is made, it can be closed when it not used. It not only solves the problem of "attacks of wild animals, floods and insects", but also solves the problem of "Staying on trees tends to cause falling, and the wind causes dryness, therefore, falling causes the wound and the dryness makes die young".

"Weaving reeds into doors" is "Using hibiscus to build houses and weaving reeds into doors" of the imperial ancestor Youchao mentioned in the classic of Han Dynasty "Spring and Autumn Prophecy". The house built on the ground has a large area, large space, convenient access, and accommodates more people. It is much safer than building a nest dwelling on trees. Because it can reduce the threat and damage caused by storms, and can also be decorated, so it is both practical and beautiful.

(3) "Plastering the wall with mud and shading with cogongrass" is also an important innovation of the imperial ancestor Youchao. It refers to using couchgrass or reeds to cover houses or weave them into walls and mix it with clay soil into mud, and apply it to the walls, lintels and roofs woven of couchgrass, reeds, etc., and fill the gaps and plaster the surfaces. In that way, the house not only can prevent ingression of wind and rain into the house and keep the room dry and warm, but also can prevent ingression of mosquitoes, insects, snakes and ants into the room through the apertures. People stay and rest safely inside the house. The house itself looks very dedicate on appearance. It is naturally much more beautiful than the rough house.

From this point of view, the materials of the early ecological buildings were as stated in the "Mythical Evolution of China's Ancient History": "teaching the people to use hibiscus to build houses and weave reeds into doors, plaster the wall with mud and shade with cogongrass to prevent wind and rain. This is the beginning of houses." That is to say, they use the acorn trees as the foundation, use hibiscus to build the house, use the reeds to weave into door leaves, and plaster the walls, door leaves and roofs, fill the gaps and plaster the surface with mud in order to shelter the wind and rain, and thus form the earliest houses. In the classic of Han Dynasty "Spring and Autumn Prophecy - Sequence of Life Calendar", it was also stated: "Youchao continued it and taught the people to use hibiscus to build houses and wove reeds into doors, plastered the wall with mud and shaded with cogongrass to prevent wind and rain. This is the beginning of houses. He was called 'ancient emperor'."

The statement is concise and clear. It not only pointed out the inheritance relationship between imperial ancestor Youchao and the first ancestor Youchao, but also clearly recorded the construction materials required to be used for building the house on the ground and the construction procedures, etc., even the appearance of the house was vividly presented on paper.

\section{APPLICATION OF REGIONAL NATURAL MATERIALS IN ECOLOGICAL BUILDINGS}

The ecosystem of human beings is a combination of human-centered life systems and environmental systems in a specific space. It refers to the dissipative structure formed through synergic effect of a number of constituent elements or subsystems in related states in the space-time where people coexist [4]. Today, the selection of regional natural materials in the category of design thinking based on practical functions and aesthetic spirits lays more focus on interest of concurrent practicality and aesthetic appreciation. The sustainably developing ecological buildings have become an inevitable trend in today's era.

\section{A. Ecological Thinking of Regional Natural Materials Reflected in Architectural Works}

The primitive state is connected with modern topics. Recalling the ancient Youchao culture, many contemporary ecological buildings contain the material selection and manual work of the primitive architectural elements. They all embrace the thinking of the earth, and return to the antiquisation and primitivation of human beings and the society. Unfortunately, so far, the pioneers in the study of primitive houses still concentrate on folklore studies and geography, whereas the personnel in architecture have always been ignoring the primitive dwellings with these charms and treating them as something like the animal nests.

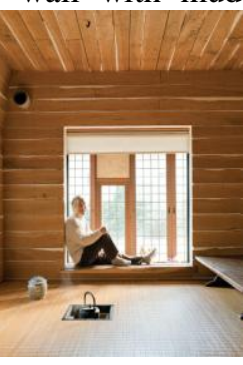

Fig. 7 Terunobu

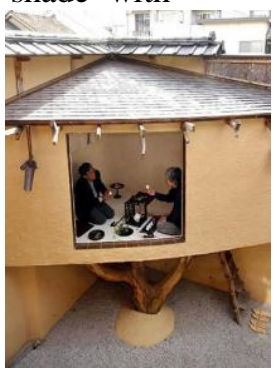

Fig. 8 Yichivate

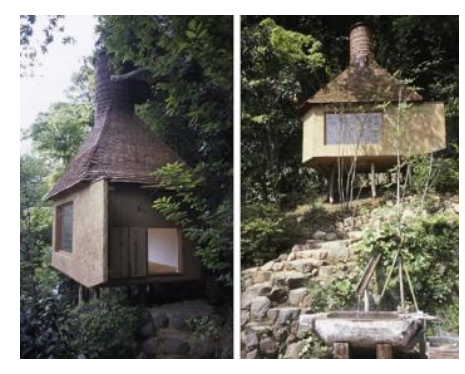

Fig. $9 \mathrm{Ku}$-an 

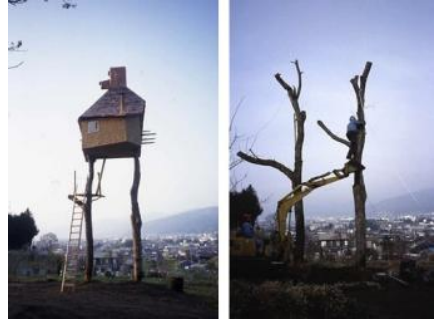

Fig. 10 Takasugi-an

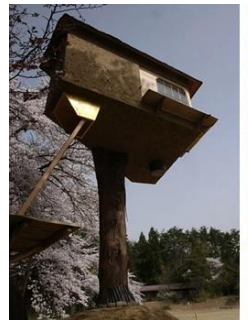

Fig. 11 Chashitsu Tetsu

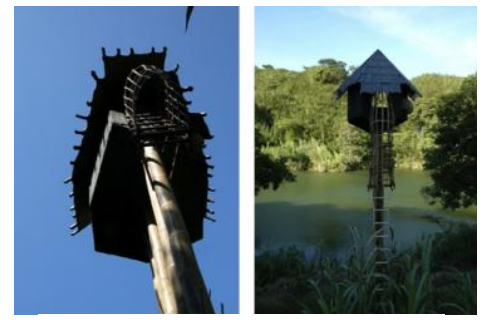

Fig. 12 River-side Teahouse
There are many designers who express their ecological thinking in regional natural materials in modern architectural works, among them, the works of Terunobu Fujimori (Fig. 7), known as "the first person who pushes modern Japanese architecture to the world's architectural stage", are the most representative: his design contains the use of regional natural materials to achieve the ecological thinking that allows poetic dwelling of human beings in the world and use of the most primitive regional natural materials as the building materials to express his avant-garde view of space. His works pursue disorder freely and emit rare warmth and modesty, thus particularly touches the desire of modern people for simple life.

\section{B. Analysis on Application of Regional Natural Materials}

Application of regional natural materials in real works, such as Terunobu Fujimori's design of small tea houses full of childlike taste and full of experiment: "Ichiyatei (One-night Teahouse)" (Fig. 8), "Ku-an (Rectangular Teahouse)" (Fig. 9), and "Takasugi-an (Too-high Teahouse" (Fig. 10), "Chashitsu Tetsu (Teahouse Tetsu)" (Fig. 11), "River-side Teahouse" (Fig. 12), etc. For example, the selection of regional natural materials for Takasugi-an, which has attracted wide attention, is strikingly similar to the idea of material selection in Youchao culture. The original ecological trees used as building materials, and the textures of streams, rocks and trees convey the dialogue between objects and people calls for the product to respect nature. Performance state, such as the color, texture, hardness, weight, roughness, warmth, etc. allow both the designer and users to intuitively grasp and aesthetically appreciate the quality features.

Fujimori's design thinking and works are the deconstruction of various design schools in the history of architecture. For example, from "Casa Dandelion" (Fig. 13) which was experimented with his own house and other works, it can be seen: natural elements such as unprocessed plants, wood and stones, etc. are the focus of buildings in visual and structural aspects. It may not belong to any period in the history of architecture, but it cannot avoid the original concept of the design. It also reflects the architectural concept of "Craft Revival" and reminds people to think about the sustainability of building materials and the availability of local materials, and influences the current and future industrialized production.

In short, by tracing back to the creation origin of the first ancestor Youchao and comparing with Fujimori's ecological buildings, it can be found that reducing the consumption of resources and energy, reducing the pollution to the environment, and recycling of used and waste materials are particularly important for sustainable development. Today's ecological design is linked to economic benefits, ecological benefits and social benefits. Resource conservation, reduction of transport costs, and reduction of wastes all can contribute to the protection of the environment. How to realize the selection of regional natural materials has become the thinking direction of ecological buildings under the social demand of low carbon and energy conservation. Studying the theoretical significance of the view of ecological culture recovering original simplicity and the view of survival value as well as the evolution of design thinking will be helpful to the development of the future architectural forms in accordance with ecological laws, broadening the horizon of technology, and achieving a harmonious coexistence between man and nature.

\section{REFERENCES}

[1] Written by Terunobu Fujimori, translated by Jing Ruiqin: "What is Architecture - Terunobu Fujimori's Thinking of Buildings", Shanghai People's Fine Arts Publishing House, 2015 edition, p. 150.

[2] Wen Renjun: "Translation and Annotation of Artificers' Record", Shanghai Classics Publishing House, 1993 edition, p. 117.

[3] Li Chaode: "Design Aesthetics", Anhui Fine Arts Publishing House, 2004 edition, p. 101.

[4] Xu Hengchun: "Design Aesthetics", Tsinghua University Press, 2013, p. 103. 